\title{
Some Aspects on Hydrocarbon-fueled RBCC Engines for a TSTO Launch Vehicle
}

\author{
By Sadatake TomioKA, Kan KobAyAshi, Toshihito SAIto, Kanenori KATO, Masatoshi KoderA and Kouichiro TANI \\ Kakuda Space Center, Japan Aerospace Exploration Agency, Kakuda, Japan \\ (Received July 31st, 2015)

\begin{abstract}
Engine system analysis upon a Rocket-Based Combined Cycle (RBCC) engine for the booster stage of a TSTO launch vehicle was conducted, to evaluate the effects of hydrocarbon fuel type upon the performance of the engine and the whole launch vehicle. A higher thrust and cooling performance with methane was shown, while some technical challenges were also noted. Combination of the scramjet flow pass and the rocket engines, i.e., rocket engine being embedded into the scramjet flow pass or separately mounted to the airframe, was varied to show that
\end{abstract} \\ the separated configuration mitigated cooling problem, and resulted in a better performance for mid-speed regime.
}

Key Words: RBCC Engines, TSTO Launch Vehicle, System Analysis

\section{Nomenclature}

$\begin{array}{ll}A R_{\text {ram }} & : \text { ramjet-duct expansion ratio } \\ I_{s p}, I_{s} p_{e} & : \text { specific impulse, effective Isp } \\ L_{\text {ram }} & : \text { ramjet-duct length } \\ M & : \text { Mach number } \\ O / F & : \text { mixture ratio (oxygen/fuel mass ratio) } \\ q & : \text { dynamic pressure } \\ t w & : \text { wall temperature } \\ V, \Delta V & : \text { velocity, velocity increment } \\ W & : \text { weight } \\ X & : \text { streamwise location from leading edge } \\ \phi & : \text { equivalence ratio } \\ \text { bscripts } & : \text { ejector-jet mode } \\ \text { ej } & : \text { ramjet mode } \\ \text { rm } & : \text { scramjet mode } \\ \text { sc } & : \text { flight or rocket stagnant conditions } \\ 0 & : \text { flow station index, see Fig. } 2 \\ 1-9 & : \text { final (booster burn out) } \\ \text { f } & : \text { initial (take-off) } \\ \text { i } & \end{array}$

\section{Introduction}

Combination of a scramjet flow-pass (conversingdiverging duct termed as ramjet-duct) with embedded rocket engines (the combined system termed as Rocket Based Combined Cycle engine, Ref. 1) are expected to be the most effective propulsion system for booster period of launch vehicles.

Various operation conditions are required to attain the maximum acceleration of the launch vehicle with the combined cycle engine, i.e., an ejector-jet mode operation at low speed range (take-off to supersonic) for initial acceleration with thrust gain due to air-augmentation effects, a ramjet-mode operation (dual-mode combustion in the scramjet flow pass, supersonic to hypersonic) with a reduced rocket engine output for acceleration with the best specific impulse (Isp) due to air-breathing effects, and a scramjet-mode operation (hypersonic) with rather high rocket engine output for final acceleration with some Isp gains due to air-augmentation effects.

At the Japan Aerospace Exploration Agency (JAXA), so-called reference system targeting the fully reusable Two-Stage-To-Orbit (TSTO) vehicle is under system design phase. ${ }^{2}$ One feature of this system is to apply hydrocarbon fuel (namely ethanol) for inexpensive operation and good packaging of the vehicle design (Fig. 1 , as an example).

In the previous studies, optimization upon the RBCC engine configurations and operational conditions, ${ }^{3)}$ as well as the booster vehicles sizing ${ }^{4)}$ were conducted. The former study showed that the ramjet-duct contraction ratio (in terms of inlet design Mach number) and expansion ratio of both embedded rocket engine nozzle and ramjet-duct had optimal values. The latter study showed a smaller vehicle size resulted in a smaller ramjet-duct thrust to embedded rocket engine thrust ratio to reduce the effectiveness of the air-breathing benefit upon the launch vehicle system. For a fixed wave-rider like orbiter stage weighted 75 tons, the minimum booster stage (an airplane-like design termed as NAL-type 0 configuration, Ref. 5) size was $40 \mathrm{~m}$ in length with a total take-off weight of 650 tons.

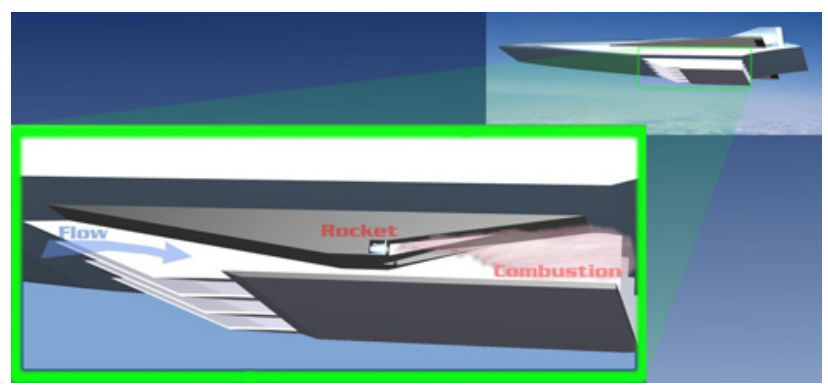

Fig. 1. Booster stage image. 


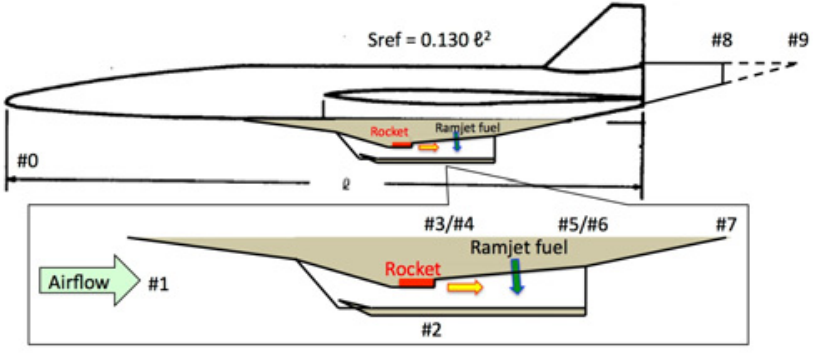

Fig. 2. Schematics of booster and RBCC configurations.

In the present study, further analyses were carried out in terms of fuel type and engine cycle. Other hydrocarbon fuels than ethanol, namely methane and kerosene (JET A), were compared to ethanol targeted in the previous studies. Thermal balance was especially emphasized in the previous study, as it can be the key design issue in the case of hydrocarbon fuel. ${ }^{6}$ )

For a selected fuel, engine cycle was varied, i.e., the embedded rocket design was compared to the separately mounted design (the scramjet engine at the belly of the vehicle and the rocket engine at the vehicles base).

\section{Engine Design and Prediction Methods}

In this chapter, major differences in the flow pass design as well as the performance prediction methods from the previous study (Ref. 3) are highlighted. Figure 2 shows the schematics of the booster airframe and engine configurations, RBCC units are mounted side-by-side under the airframe belly. Compression by the fore-body of the vehicle was not taken into account as the airflow aligned with the airframe axis before reaching the inlet compression ramps. On the other hand, the aft-body was fully used for expansion, with the exception when the rocket engine was embedded at the expansion part at the location designated as station \#8 in Fig. 2.

\subsection{Modification on performance prediction}

Engine performance prediction methods are essentially the same to the previous ones, different methods for different operation modes. The major difference was the thrust prediction in the external nozzle, as will be described below.

For the ramjet-mode and scramjet-mode operations, incoming flow state was calculated with two-dimensional wave-pattern calculations. Within the isolator section upstream of the combustor section of the ramjet-duct, one-dimensionally averaged flow status was attained as the input to the combustor calculation. The airflow was mixed with the rocket plume to form a uniform supersonic incoming flow to the combustor section of the ramjet-duct. For the ramjet-mode operation, the mixed flow was decelerated to subsonic through a normal shock wave located at the onset of the combustor section. The subsonic flow then diffused within the diverging portion of the ramjet-duct to the designated heat release region, where the mixed flow was thermally choked with released heat. The heat release location was so-selected that the following effective impulse function $\left(I s p_{e}\right)$,

$I s p_{e}=I s p \times(1-$ 'vehicle drag' / 'engine thrust' $)$

became maximum for the best acceleration. Note that this value is equivalent to rocket engine's Isp in vacuum condition. Drag coefficients and reference areas of both booster and orbiter vehicles will be found in Ref. 4 .

For the scramjet-mode operation, ramjet fuel was fed through the rocket exhaust, i.e., the rocket chamber also functioned as a gas generator. The mixture ratio $(\mathrm{O} / \mathrm{F})$ of the rocket plume was so selected that the resulting supersonic flow generated the maximum $I s p_{e}$.

For the ejector-mode operation, airflow flow rate was so determined that either the airflow Mach number or the mixed flow (the airflow and the rocket plume mixed completely and instantaneously) Mach number was limited to unity. Then the heat release process was identical to that for the ramjet-mode operation.

Again, the major difference in the prediction method was about the external nozzle. In the previous study, the flow was bounded by imaginable boundaries parallel to the ramjet-duct cowl and the sidewalls. In the present study, a free boundary was given ${ }^{7)}$ so that the exhaust flow from the ramjet-duct expanded to the ambient

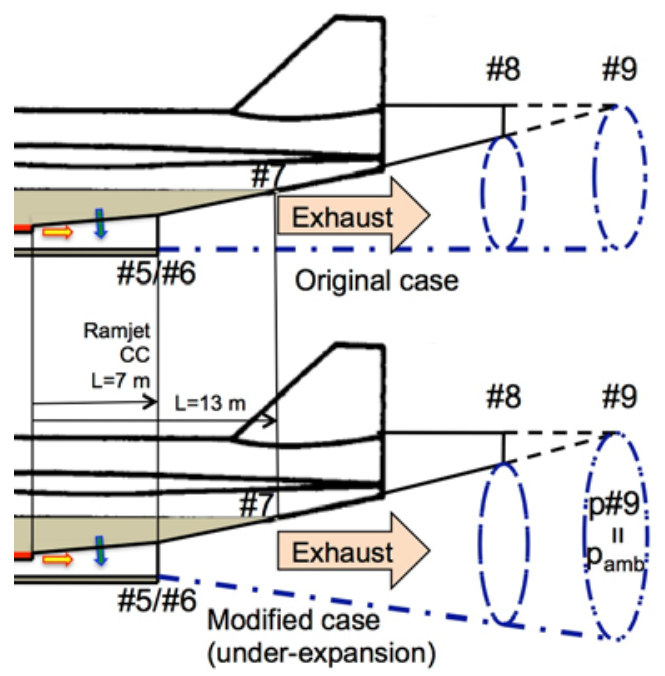

Fig. 3. External nozzle flow prediction schematics.

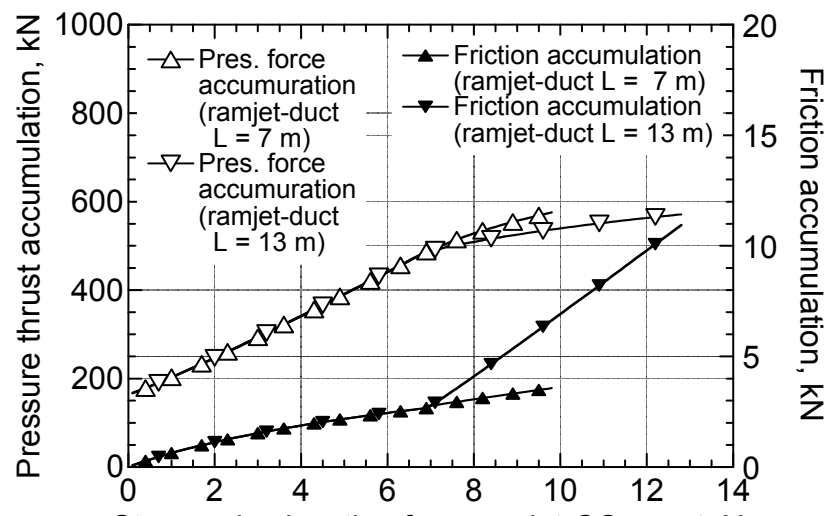

Streamwise location from ramjet-CC onset, $\mathrm{X} \mathrm{m}$

Fig. 4. Pressure thrust and friction drag accumulation. 
pressure at the exit of the full external nozzle (i.e., the cross section of the whole vehicle acted as the external nozzle). The difference was shown schematically in Fig. 3. In the case with nozzle truncation, the free boundary was hold so that the exhaust flow expanded accordingly to a pressure level different from the ambient pressure.

Calculation showed that the exhaust flow was underexpanded condition in both ramjet-mode and scramjetmode operations. In these cases, the ramjet-duct would produce a higher pressure-thrust than the external nozzle. However, skin friction within the ramjet-duct overcame the pressure-thrust gain (an example of variations of pressure thrust and friction drag accumulations were shown in Fig. 4 for various ramjet-duct combustor length), so that the ramjet-duct was truncated as will be mentioned in section 2.3. Here, skin friction was estimated with van Driest method. ${ }^{8)}$

\subsection{Thermal balance evaluation}

Heat flux to the ramjet-duct wall was estimated by above mentioned friction coefficient and Reynolds analogy. In the calculation, the wall temperature was set to be as below;

$\mathrm{t}_{\mathrm{w}}=$ ('fuel max temp.'+'fuel storage temp.')/2+50 K (2) where $50 \mathrm{~K}$ is approximated temperature drop within the metal wall and coolant thermal boundary layer. The maximum value of fuel temperature was set accordingly to the fuel properties, and will be described later.

Open surface such as the inlet ramp and the external nozzle ramp was expected to be radiation-cooled. Heat flux to the rocket chamber wall was evaluated with so-called Bartz method. ${ }^{9)}$

Airframe leading edge and ramjet-duct cowl leading edge was actively cooled, heat flux being evaluated by so called D.K.R. method. ${ }^{10)}$ In the calculation, leading edge radius was set to be $0.1 \mathrm{~m}$, and its length was set equal to the vehicle width ( $8 \mathrm{~m}$ in the case with airframe length of $40 \mathrm{~m}$ ).

Thermal balance was evaluated by matching the heat sink by fuel and estimated heat transfer. If excessive fuel was required for cooling, it was assumed to be dumped into atmosphere, i.e., to have no contribution to the thrust production, as too fuel rich condition within the ramjet-duct might suppress the chemical reaction.

\subsection{Engine design and operations}

In the previous study, a moderate contraction with single ramp configuration (inlet full capture at $\mathrm{M}_{0}=6$ ) was found to give the best acceleration performance for a single ramp compression case. In the present study, the compression ramp was two-staged while the full capture Mach number $\left(\mathrm{M}_{0}=6\right)$ as well as the starting Mach number $\left(\mathrm{M}_{0}=3\right.$, beyond which the engine was under the ramjet-mode operation) was the same to the previous study. The resulting contraction ratio was 5.0, with the first-stage ramp angle / geometrical contraction ratio of 6.6 degrees / 1.3, and second-stage ramp angle / contraction ratio of 15.7 degrees / 3.8, with almost equal streamwise length of the two ramps.

The ramjet-duct combustor had single ramp expansion

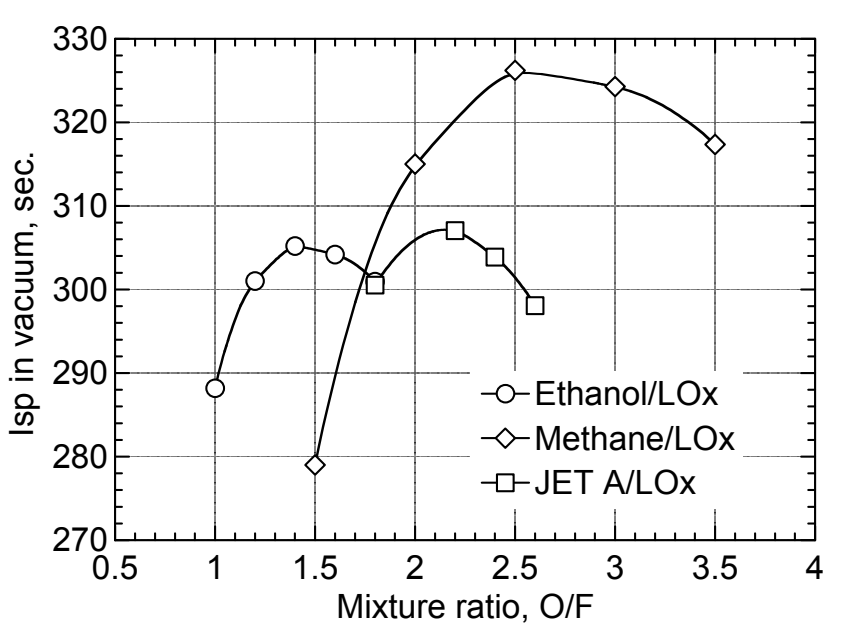

Fig. 5. Rocket engine Isp in vacuum with.

at an angle of 10 degrees. $^{11)}$ In the previous study at JAXA - Kakuda Space Center, ${ }^{12)}$ two straight ducts, a mixing duct to attain ejector effects (section \#3 \#4 in Fig. 2 ) and another straight duct to sustain thermal choking (section \#5 \#6) at the ramjet-duct exit. However, both ducts were omitted in the present study as the thermal balance would be the most severe restriction. The length of the ramjet-duct combustor was so selected (estimated with $1 \mathrm{~m}$ interval) that thermal choking at the duct exit would result in the best acceleration performance at $\mathrm{M}_{0}=3$.

The external nozzle had a single ramp expansion at an angle of 20 degrees to reduce the engine weight. Radiation cooling was expected for the external nozzle, setting composite material upon the surface to reduce the heat flux level.

Three RBCC units stretched in full span of the NAL-type 0 vehicle, with $10 \%$ wall thickness on both sides, resulting in a duct width of $2.02 \mathrm{~m}$. Engine height was $3.66 \mathrm{~m}$, so that engine total length would fit to the NAL-type 0 fuselage.

Embedded rocket engine was so designed that total thrust was $4.5 \mathrm{kN}$ (about $70 \%$ of take-off weight deduced in the previous study), and each RBCC unit contained 4 rocket chambers. They were operated at a chamber pressure of $6 \mathrm{MPa}$ to ensure a sufficiently long duration. Expansion ratio of the rocket nozzle was so set that the pressure at the nozzle exit was about $100 \mathrm{kPa}$ (nozzle expansion ratio of 8 ). The resulting expansion ratio of the ramjet duct at the rocket base was 1.92. Length of the rocket combustion chamber was so designed to fulfill the characteristic chamber length of $1.27 \mathrm{~m}$.

Design mixture ratio was so selected to show the best vacuum $I s p$. Figure 5 shows the variation of vacuum $I s p$ against mixture ratio. For the ramjet-mode operation, chamber pressure was reduced to $1 / 10$ while the mixture ratio was also for the best vacuum Isp. For the ejector-mode operation, $\mathrm{O} / \mathrm{F}$ was set to be high (equivalence ratio of $1.8,3.5$ and 3.0 for ethanol-, methane-, and JET A-fueled cases, respectively), as airflow / rocket exhaust mixing and combustion was found to increase total pressure loss and to reduce the airflow rate. For the scramjet-mode operation, again, 
mixture ratio was so varied to change the fuel flow rate for ramjet combustion under constant chamber pressure. The ramjet-mode operation was switched to the scramjet-mode operation at the flight Mach number where the $I s p_{e}$ with the scramjet-mode operation exceeded that with the ramjet-mode operation (typically $\mathrm{M}_{0}=5$ in the present study).

\section{Effects of Fuel Type on the Vehicle Performance}

In the present study, a simple system analysis was conducted. Angle of attack was set to be zero to attain incoming flow conditions as well as the vehicle drag. After takeoff, the vehicle was supposed to fly at a dynamic pressure of $50 \mathrm{kPa}$ till the end of the ramjet-mode regime. Then the vehicle gained altitude to fly at a dynamic pressure of $10 \mathrm{kPa}$, as the reduction in the vehicle drag overcame the reduction in thrust production in lower dynamic pressure environment. Effective Isp was calculated at each flight Mach number and integrated along the trajectory for $\mathrm{M}_{0}=0$ to 12 (booster separation velocity), to give initial $\left(\mathrm{W}_{\mathrm{i}}\right)$ to final $\left(\mathrm{W}_{\mathrm{f}}\right)$ launch system mass ratio through the equation below,

$$
\Delta \mathrm{V}=I s p_{e} \times \ln \left(\mathrm{W}_{\mathrm{i}} / \mathrm{W}_{\mathrm{f}}\right)
$$

\subsection{Description of fuel properties}

In the present study, the most important properties of the fuel were net heating value and heat sink capacity. Figure 6 shows variations of specific heat of each fuel as a function of temperature. To evaluate heat sink capacity, the maximum value of fuel temperature after regenerative cooling should be nicely determined.

First of all, wall temperature was assumed to be less than $600 \mathrm{~K}$ to ensure a sufficiently long duration of the cooling panel structure, so that the maximum value of temperature should be around $550 \mathrm{~K}$. As shown in Fig. 5, ethanol showed sudden increase in the specific heat around its critical temperature. This sudden increase makes the thermal design very difficult, so that the maximum value of temperature for the ethanol was set at $500 \mathrm{~K}$. On the other hand, this sudden increase appeared around $200 \mathrm{~K}$ for the methane case, so that one could expect that this excessive heat absorption around critical temperature can be utilized in the methane case, so that the maximum value of temperature was set at $550 \mathrm{~K}$. Critical temperature of JET A fuel was about $690 \mathrm{~K}$, so that the sudden variation of the specific was above the $550 \mathrm{~K}$ limit. One should note that JET A fuel causes thermal coking beyond $440 \mathrm{~K}$, so that either thermal stability additive or deoxygenation is required to ensure the long duration. ${ }^{6)}$

Integration of specific heat over the temperature range gives heat sink capability. Table 1 summarizes the heat sink capability, net heating value, and ratio of heat sink capacity over the net heating value. Also cryogenic methane seems to be good for cooling, heat-sink to net heating ratio was almost identical to ethanol, so that cooling capacity is almost the same to ethanol in system

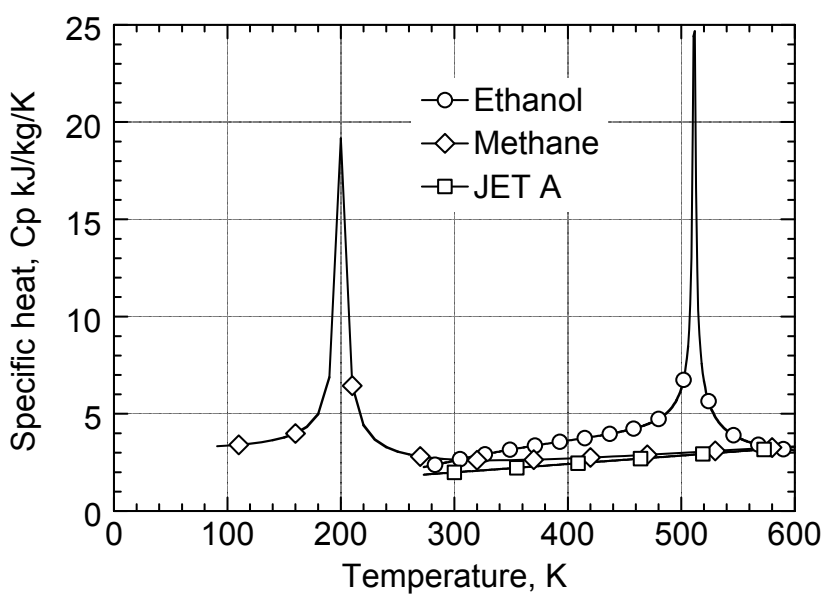

Fig. 6. Specific heat of various fuels.

Table 1. Thermal properties of various fuels.

\begin{tabular}{ccccc}
\hline \hline $\begin{array}{c}\text { Fuel } \\
\text { type }\end{array}$ & $\begin{array}{c}\text { Temp. } \\
\text { range }\end{array}$ & $\begin{array}{c}\text { Heat sink } \\
\mathrm{kJ} / \mathrm{kg}\end{array}$ & $\begin{array}{c}\text { Net } \\
\text { heating } \\
\mathrm{kJ} . \mathrm{kg}\end{array}$ & $\begin{array}{c}\text { Heat-sink/ } \\
\text { net-heating }\end{array}$ \\
\hline Ethanol & $280-500 \mathrm{~K}$ & 794 & 26800 & 0.030 \\
Methane & $110-550 \mathrm{~K}$ & 1590 & 50000 & 0.032 \\
JET A & $280-550 \mathrm{~K}$ & 671 & 43100 & 0.016 \\
\hline \hline
\end{tabular}

point of view. On the other hand, JET A has sizably lower heat sink to net heating ratio, so that cooling capability can run short. Kerosene like JET A is known to cause thermal decomposition (cracking) to further absorb heat, ${ }^{6}$ the heat sink value being as high as $2500 \mathrm{~kJ} / \mathrm{kg}$, so that cooling capability can be more than methane. A major problem is that the thermal decomposition requires very elevated temperature (as high as $800 \mathrm{~K}$ ), so that cooling channel material should be nicely selected and/or catalysis should be utilized to lower the temperature level. Also, surface deposition of pyrolytic substance should be avoided to ensure reusability of the cooling channel structure.

\subsection{Engine and vehicle performances}

The difference on combustion gas properties resulted in a slight difference in the ramjet-duct design duct length $\left(\mathrm{L}_{\mathrm{ram}}\right)$ and expansion ratio $\left(\mathrm{AR}_{\mathrm{ram}}\right)$ for the best $I s p_{e}$ as follows;

Ethanol and JET A cases, $\mathrm{L}_{\mathrm{ram}}=7 \mathrm{~m}, \mathrm{AR}_{\mathrm{ram}}=1.88$

Methane case, $\mathrm{L}_{\mathrm{ram}}=8 \mathrm{~m}, \mathrm{AR}_{\mathrm{ram}}=2.00$

Figures 7 show the variation of $I s p$ and $I s p_{e}$ with equivalence ratio (ramjet fuel to airflow), a) at $\mathrm{M}_{0}=4$ and $\mathrm{q}_{0}=50 \mathrm{kPa}$ (ramjet-mode), b) at $\mathrm{M}_{0}=6$ and $\mathrm{q}_{0}=50 \mathrm{kPa}$ (scramjet-mode), and $\mathrm{c}$ ) at $\mathrm{M}_{0}=6$ and $\mathrm{q}_{0}=10 \mathrm{kPa}$ (scramjet-mode), respectively. Heat balance was not considered. As shown in Fig. 7a, Isp was of the highest with methane, and of the lowest with ethanol as the net heating order in Table 1 suggested, while the difference was not that large compared to the net heating value. The engine $I s p$ tended to have the maximum value on fuel lean side, while $I s p_{e}$ had the maximum value at around equivalence ratio of unity to slightly fuel rich region. As the majority of the thrust production was by the 


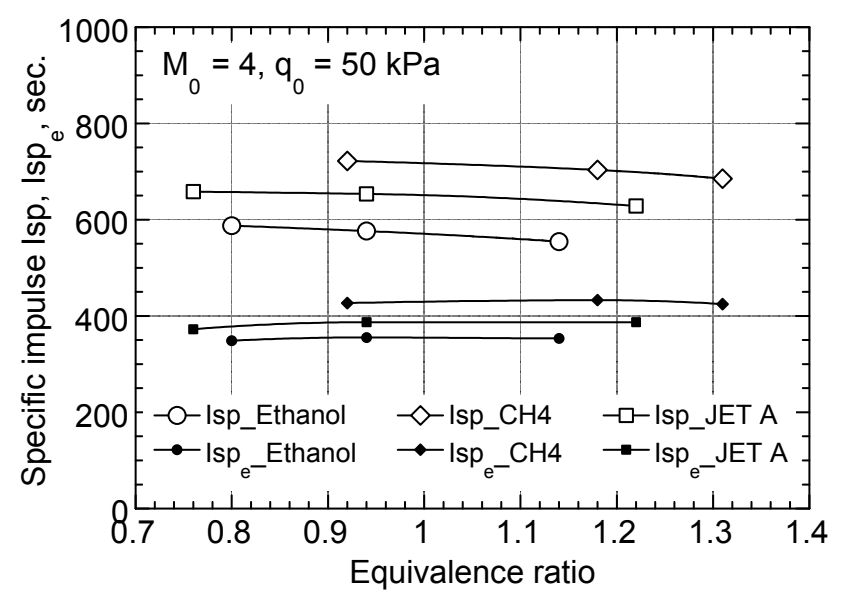

Fig. 7a. Variation of Isp and $I_{\mathrm{s}} \mathrm{e}_{\mathrm{e}}$ with ramjet-fuel equivalence ratio at $\mathrm{M}_{0}=4$ (ramjet-mode) at flight $\mathrm{q}_{0}=50 \mathrm{kPa}$.

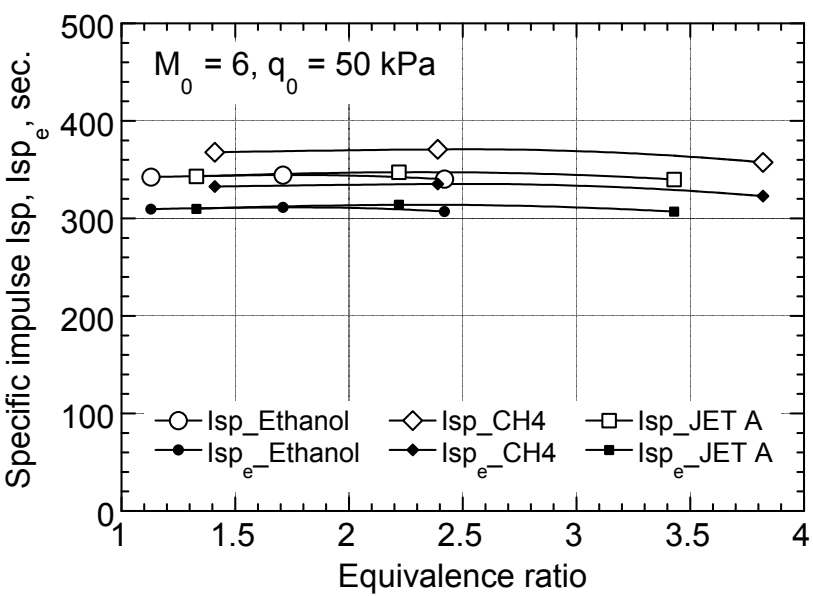

Fig. 7b. Variation of Isp and Ispe with ramjet-fuel equivalence ratio at $\mathrm{M}_{0}=6$ (scramjet-mode) at flight $\mathrm{q}_{0}=50 \mathrm{kPa}$.

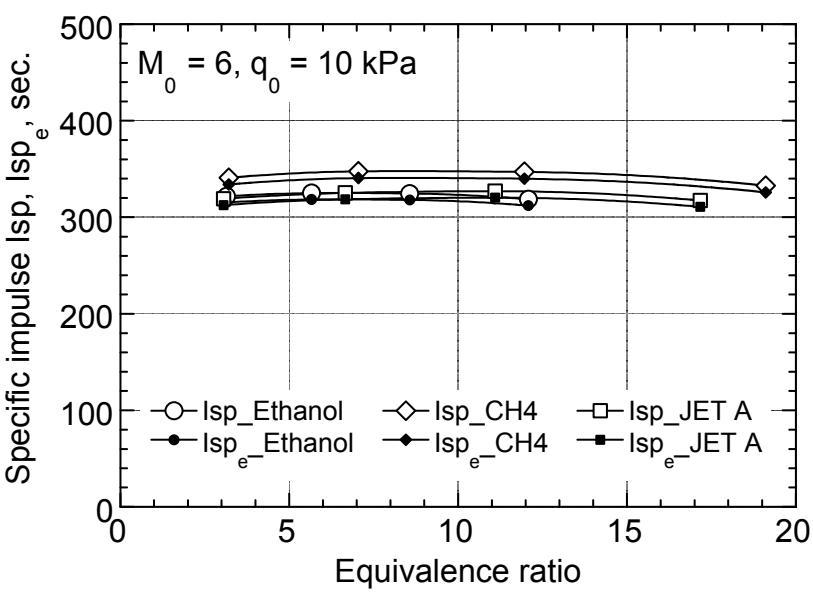

Fig. 7c. Variation of Isp and $\mathrm{Isp}_{\mathrm{e}}$ with ramjet-fuel equivalence ratio at $\mathrm{M}_{0}=6$ (scramjet-mode) at flight $\mathrm{q}_{0}=10 \mathrm{kPa}$.

ramjet-duct in this operation mode, both thrust production and vehicle drag were proportional to the flight dynamic pressure, so that the $I s p_{e}$ level should be insensitive to the dynamic pressure. However, the heavy system weight in the initial stage should require high dynamic pressure to sustain sufficient lift.

In the scramjet-mode operation, situations are different. Note that the equivalence ratio was defined by ramjet-fuel flow rate against the airflow. In this mode, ramjet fuel was injected through the rocket chamber, so that the equivalence ratio could be as high as 10 20 in low dynamic pressure (airflow flow rate) case. Even in the high dynamic pressure condition (Fig. 7b), JET A case and ethanol case show almost identical trace as the major portion of the thrust production was through the rocket chamber, and rocket chamber Isp in both cases were almost identical as shown in Fig. 5. The resulted engine $I s p$ in Fig. 7c are sizably higher than the rocket engine values in Fig. 5 even at this low dynamic pressure, because the ramjet-duct acted as extended nozzle to the rocket plume to provide substantially high expansion ratio of 34 .

Difference in the engine Isp between Figs. $7 \mathrm{~b}$ and $7 \mathrm{c}$ are mainly due to the ramjet-duct thrust production, about $20 \mathrm{sec}$. The difference between the engine Isp and $I s p_{e}$ were reduced in this mode as the thrust level increased against the vehicle drag level. Comparison between Figs. $7 \mathrm{~b}$ and $7 \mathrm{c}$ shows that $I s p_{e}$ increased slightly at the lower dynamic pressure environment (Fig. 7c), as the reduction in vehicle drag against the engine thrust (less sensitive to the dynamic pressure than the vehicle drag) worked favorably. The lower dynamic pressure also worked favorably to reduce the heat transfer to the leading edges and the engine wall.

Figures 8 show the variations of Isp and Ispe, respectively, with $\mathrm{M}_{0}$. Both cases without (open symbol) and with (solid symbols) heat balance consideration were presented, the excess fuel against cooling requirement being dumped in the latter case.

In the case with methane fuel, heat unbalance was never experienced, so that the whole engine was operated at optimum condition throughout the trajectory. In the case with ethanol fuel, heat unbalance was experienced in the scramjet-mode regime, so that the engine should be operated at rather fuel rich (non optimal in terms of rocket chamber operation condition), while fuel dumping could be avoided somehow. In the case with JET A fuel, on the other hand, fuel dumping was inevitable even at $\mathrm{M}_{0}=$ 4 (ramjet-mode), and a sizable reduction in $I s p_{e}$ in the ejector-mode region was observed.

Integration of the results in Fig. 8b along the trajectory resulted in the booster propellant to system initial mass ratio of $68.8 \%, 65.8 \%$, and $68.2 \%$ for the ethanol-, methane-, and JET A-fueled cases, respectively without heat balance consideration, and $69.1 \%, 65.8 \%$, and $70.5 \%$ with the heat balance consideration. As the results, methane was the most favorable fuel, while the packaging and handling of cryogenic fuel can be system demerits. Also, methane is notorious having very long ignition delay, so that higher output and/or higher $\mathrm{O} / \mathrm{F}$ setting on the rocket engine operation condition might be required during the ramjet-mode operation. 


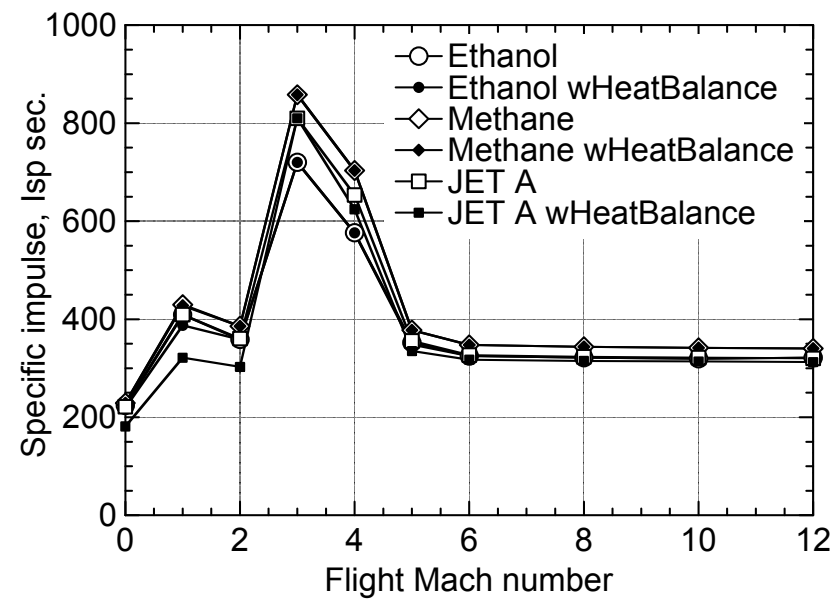

Fig. 8a. Variation of Isp with $\mathrm{M}_{0}$ with various fuels.

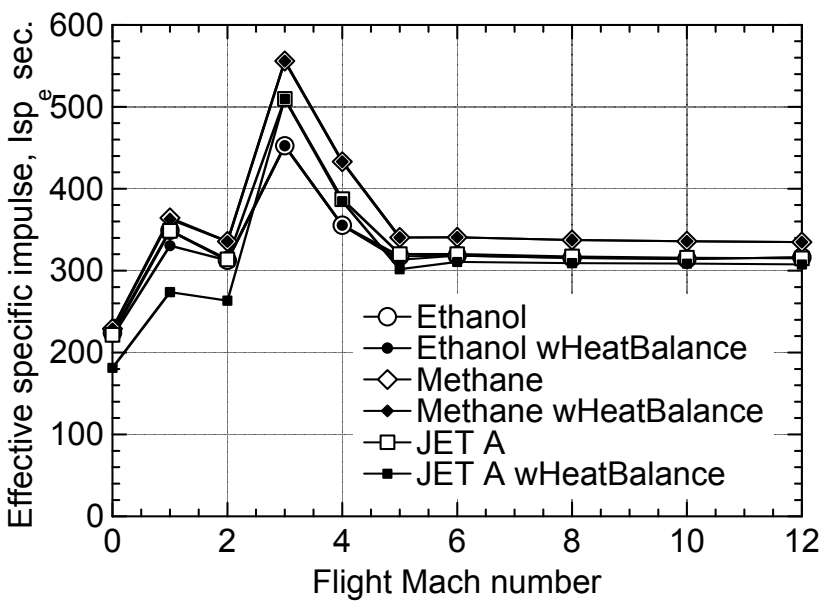

Fig. 8b. Variation of $\mathrm{Isp}_{\mathrm{e}}$ with $\mathrm{M}_{0}$ with various fuels.

As storable fuel, JET A was found to be favorable if the limitation in cooling capability could be avoided via the thermal cracking. ${ }^{6}$ ) In terms of packaging, propellant volume fraction against the estimated available tanks' volume $\left(580 \mathrm{~m}^{3}\right)$ in the current design ${ }^{3)}$ was $80 \%, 95 \%$, and $75 \%$ for the ethanol-, methane-, and JET A cases, respectively, without heat balance consideration. Thus, the system size and weight could be further reduced with JET A fuel. Note that the thermal cracking, however, should not damage the engine life duration and the reusability due to coking upon the cooling channel surface and /or upon the turbine surface.

\subsection{Further consideration required}

System weight penalties for installing cryogenic methane tank should be evaluated by detailed packaging consideration. Possibility of integral tank usage in hypersonic flight with heat load to the airframe skin should be evaluated to quantify the system weight merit of storable fuels, especially for ethanol known to attack aluminum alloy and seals at elevated temperature.

Chemical kinetic calculation should be performed to evaluate the necessary rocket engine operation conditions during the ramjet-mode operation, especially for the methane case, as the rocket plume was expected to act as ignition source (the rocket engine as a torch igniter) for the ramjet-fuel separately injected.

Possibility of thermal cracking for cooling while ensuring cooling panel durability should be pursued to discuss about possible use of aviation fuel.

\section{Effects of Engine Configurations on the Vehicle Performance}

The severe cooling requirement on the ramjet-duct even at low dynamic pressure condition was due to the rocket exhaust flowing within the ramjet-duct. In this chapter, a separated system, i.e., a scramjet engine and rocket engines mounted separately, was adopted and its performance including restriction due the cooling requirement was compared to that with the integrated configuration shown in Chap. 3. JET A fuel was selected for this evaluation as JET A-fueled case showed the most severe deficit in performance due to cooling requirement in the case with the integrated configuration.

\subsection{Integrated design vs. separated design}

Inlet and isolator portion of the scramjet flow pass was identical to that of the integrated configuration. A single ramp expansion (ramp angle of 10 degrees) was given to the following combustor. The combustor was truncated, following the same design method (see Sec. 2.3) to that in the integrated configuration case.

The difference in geometry and absence in rocket exhaust in the separated configuration resulted in a slight difference in the length of the ramjet-duct combustor ( $\mathrm{L}_{\mathrm{ram}}$, isolator length excluded) and in a sizable difference in the combustor expansion ratio $\left(\mathrm{AR}_{\mathrm{ram}}\right)$ for the best $I s p_{e}$ as follows;

Integrated configuration, $\mathrm{L}_{\mathrm{ram}}=7 \mathrm{~m}, \mathrm{AR}_{\mathrm{ram}}=1.88$

Separated configuration, $\mathrm{Lram}_{\mathrm{ra}}=6 \mathrm{~m}, \mathrm{AR}_{\mathrm{ram}}=2.45$

The combustor length was larger for the integrated configuration as the ramjet duct experienced expansion at the rocket base with area ratio of 1.92 .

The external nozzle had the same angle of 20 degrees to that in the integrated configuration case. The external nozzle was truncated to make space for the rocket engines mounted at the base of the external nozzle. Identical design was given to the mounted rocket engine to that embedded within the integrated configuration, i.e., the rocket exhaust static pressure was about sea-level atmospheric pressure.

\subsection{Engine and vehicle performances}

The scramjet flow pass was operated with ramjet-mode combustion (flow features equivalent to that with the ramjet-mode operation for the integrated configuration) till $\mathrm{M}_{0}=6$. Above $\mathrm{M}_{0}=6$, thermal choking could no longer attained, so that heat release was assumed to occur at the combustor entrance immediately after fuel injection.

Figures 9 compare pressure and Mach number distributions against the cross-sectional area, between the integrated and separated configurations for a) $\mathrm{M}_{0}=4$ ramjet-mode operation at dynamic pressure of $50 \mathrm{kPa}$, and b) $M_{0}=6$ scramjet-mode operation at dynamic pressure of 


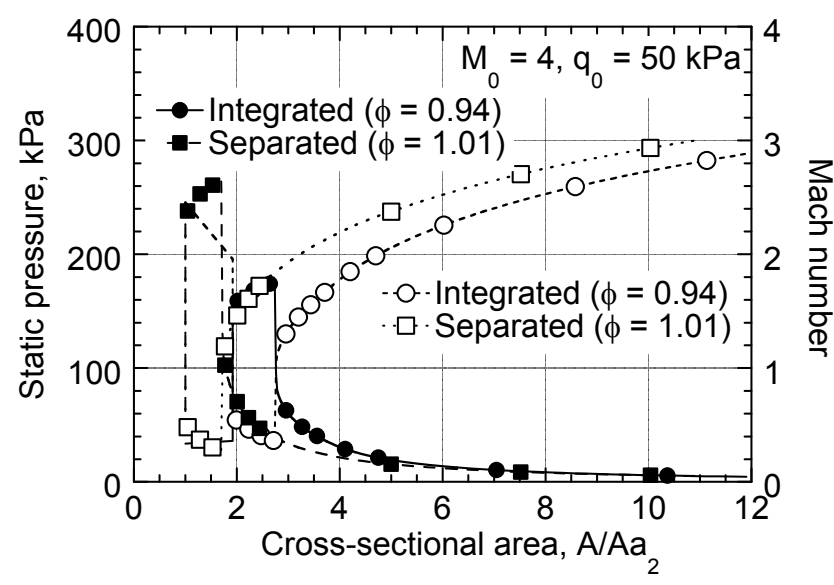

Fig. 9a. Comparison of pressure distributions at $\mathrm{M}_{0}=4$ (ramjetmode operation) at flight $\mathrm{q}_{0}=50 \mathrm{kPa}$.

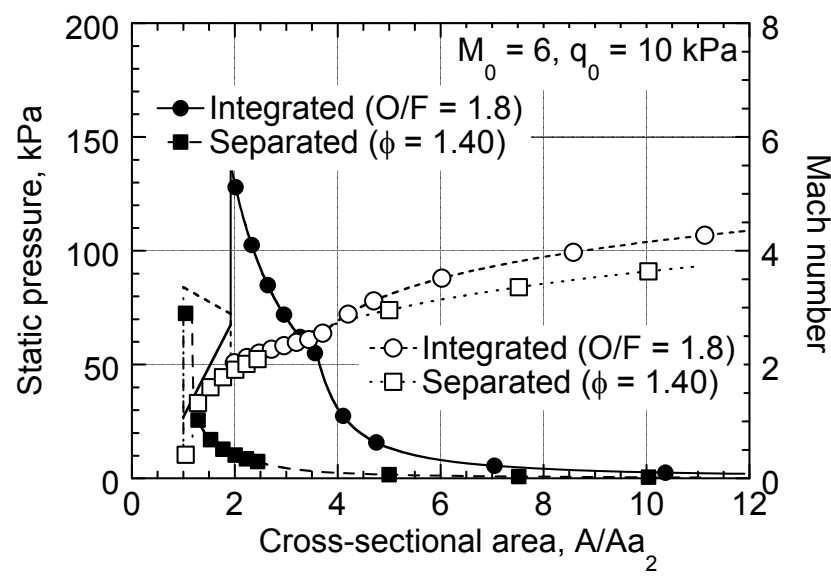

Fig. 9b. Comparison of pressure distributions at $\mathrm{M}_{0}=6$ (scramjetmode operation) at flight $\mathrm{q}_{0}=10 \mathrm{kPa}$.

$10 \mathrm{kPa}$. At $\mathrm{M}_{0}=4$, the major difference was expansion at the rocket base, i.e., rather low pressure was sustained over the rocket base for the integrated configuration case. The airflow was mixed with the rocket exhaust, resulting in total pressure loss and a reduced Mach number. Thus, pressure recovery through the shock wave was less intensive for the integrated configuration case. The resulting thrust production in the ramjet-duct (rocket thrust excluded) was about $25 \%$ less than that for the separated configuration case with almost identical fuel equivalence ratio.

At $\mathrm{M}_{0}=6$, situations were different. At first, for the integrated configuration case, thermal choking was not available because of the high momentum of the rocket exhaust. Mixing between the rocket exhaust and airflow resulted in a high pressure after mixing, and resulting high thrust production in the ramjet-duct. Note that ramjet-fuel was supplied through the rocket chamber (GG like operation), so that its momentum was also utilized for thrust production. For the separated configuration case, on the other hand, thermal choking was still attainable at this flight Mach number (became unattainable at higher Mach number to become scramjet-mode combustion), with recovered pressure level far below pressure level for the integrated case. Note that the flight dynamic pressure was low in this case as reduction in the vehicle drag worked better to attain higher $I s p_{e}$, so that the rocket exhaust to airflow mass flow ratio was about 7 (about 1.3 for dynamic pressure ratio of $50 \mathrm{kPa}$ ). Thus, thrust production within the ramjet-duct was mainly due to the expansion of the rocket exhaust for the integrated configuration case, i.e., the ramjet-duct worked as an extension nozzle to the embedded rocket engine.

The mounted rocket engine was operated at its design point (chamber pressure of $6 \mathrm{MPa}$, mixture ratio for the best vacuum $I_{s p}$ ) beyond $\mathrm{M}_{0}=6$ and below $\mathrm{M}_{0}=3$. At $\mathrm{M}_{0}=3 \sim 5$, the mounted engines was operated at chamber pressure of $0.6 \mathrm{MPa}$, and at mixture ratio for the best vacuum Isp.

Below $\mathrm{M}_{0}=3$, the inlet of the scramjet flow pass did not start, so that no fuel injection was conducted. Estimating the drag production for the unstarted scramjet flow pass was difficult, so that a very rough estimation assuming Pitot pressure on the inlet ramp and ambient pressure on the combustor and external nozzle ramps.

Figures 10 show the variations of a) Isp and b) $I s p_{e}$, respectively, with flight Mach number. Results of the integrated configuration case with heat balance consideration are also shown for comparison. Both results without (open symbol) and with (solid symbols)

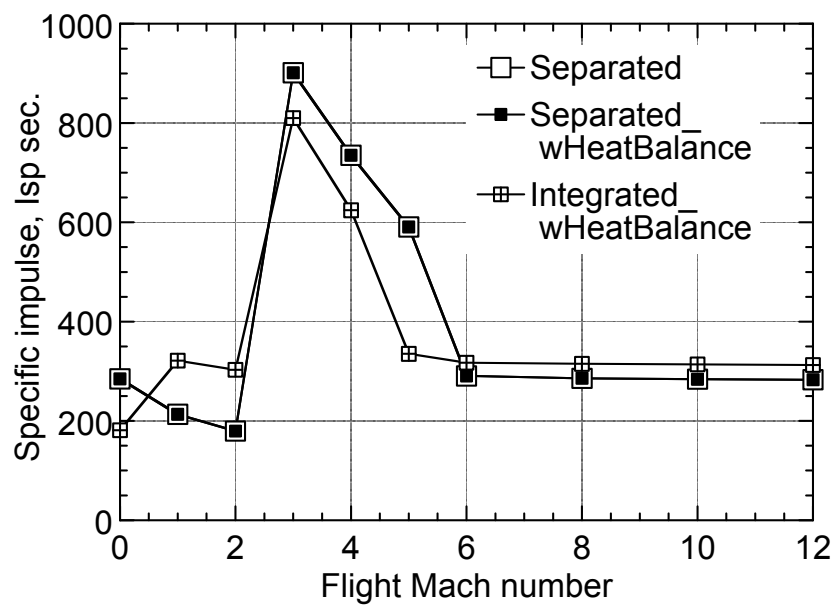

Fig. 10a. Variation of Isp with $\mathrm{M}_{0}$ with different configurations

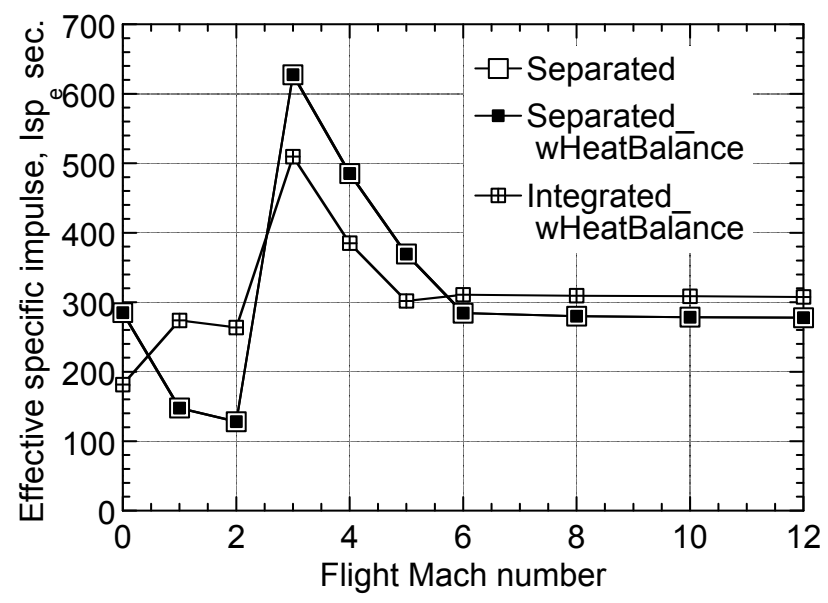

Fig. 10b. Variation of Isp $\mathrm{s}_{\mathrm{e}}$ with $\mathrm{M}_{0}$ with different configurations. 
heat balance consideration were presented. As one can see, both results show identical variation, showing that cooling requirement made no effect on the engine performance even with JET A used as the fuel for the separated configuration case, i.e., being separated from the rocket plume, the cooling requirement on the scramjet flow pass was within the cooling capacity of the ramjet fuel and the excess capacity of the rocket engine fuel. At $\mathrm{M}_{0}=6$, Ispe with the rocket engine's $100 \%$ output exceeded that with the $10 \%$ output, so that the rocket engine output was at full-throttle at $\mathrm{M}_{0}=6$ and beyond. Above $\mathrm{M}_{0}=10$, the scramjet flow pass no longer produced any thrust (Isp slightly lower than the combined case), so that the upper operation limit should be changed accordingly for better vehicle performance.

Comparison with the integrated configuration case showed that $I s p_{e}$ was sizably higher with the separated configuration in the $\mathrm{M}_{0}=3 \sim 5$ region with ramjet-mode operation, as previously mentioned. In the integrated configuration case, $I s p_{e}$ with the ramjet-mode operation became inferior to that with the scramjet-mode operation at $\mathrm{M}_{0}=5$ and mode switching took place at this Mach number. Thus, ramjet-mode operation range was widened in the separated configuration case.

Integration of the results in Fig. 10 along the trajectory resulted in the booster propellant to system initial mass ratio of $74.2 \%$, the vehicle acceleration performance was worse than that of the RBCC engine with heat balance consideration. The rough and severe drag estimation in low speed region was to be blamed. If the rocket engine thrust alone was counted (no drag from the unstarted scramjet engine), the booster propellant to system initial mass ratio decreased to $71.2 \%$. More precise drag estimation was required.

\subsection{Further consideration required}

Stage-separation speed should be assessed (namely, to be lowered) in the separated configuration case. Operation condition of the mounted rocket engine, especially the nozzle expansion ratio should be selected to give the best vehicle performance along the trajectory. The rocket engine output in the low speed region should also be selected.

\section{Conclusions}

System analysis upon a TSTO launch vehicle equipping a Rocket-Based Combined Cycle engine on its booster stage was conducted for various hydrocarbon fuels. Methane fuel showed the highest benefit, while packaging and handling should be further accessed, as well as the rocket engine operation condition acting as the torch igniter to the ramjet-fuel.

The integrated configuration (the rocket engines embedded with the scramjet flow pass) was compared to the separately mounted configuration for the JET A fuel case with severe deficit in cooling capability, to show that separately mounted configuration was beneficial to reduce cooling requirement, and increased the air-breathing effects in mid-speed range.

\section{References}

1) Kanda, T. Kudo, K.: Conceptual Study of a Combined- Cycle Engine for an Aerospace Plane, J. Propulsion and Power, 19 (2003), pp.859-867.

2) Yoshida, M., Ishimoto, S., Kimura, T., Tomioka, S., Kodera, M. Tani, K.: Future Space Transportation Vehicle Study at JAXA, IAC paper IAC-12-D2-4-2, 2012.

3) Tomioka, S., Hiraiwa, T., Saito, T., Kato, K., Kodera, M. Tani, K.: System Analysis of a Hydrocarbon-fueled RBCC Engine Applied to a TSTO Launch Vehicle, Trans. JSASS Aerospace Tech. Japan, 12, ists29 (2014), pp. Pa_91-Pa_99.

4) Tomioka, S., Kodera, M., Kato, K. Tani, K.: System Analysis on an Air-breathing Engine for the Booster-stage of a TSTO Vehicle, $57^{\text {th }}$ Conference of Space Science and Technology, 2013 (in Japanese).

5) Sakata, K., Yanagi, R., Shindo, S., Minoda, M. Nouse, H.: Conceptual Study on Air-Breathing Propulsion for Space Plane, Proceedings of the $16^{\text {th }}$ International Symposium on Space Technology and Science, Tokyo, 1988, pp. 107-112.

6) Edwards, T.: Liquid Fuels and Propellants for Aerospace Propulsion, 1903-2003, J. Propulsion and Power, 19 (2003), pp.1089-1107.

7) Masuya, G. Wakamatsu, Y.: Calculation of Scramjet, NAL-Technical Report TR-987, 1988 (in Japanese).

8) van Driest, E. R.: Turbulent Boundary Layer in Compressible Fluids, J. Aeronautical Sciences, 18 (1951), pp.145-160.

9) Bartz, D. R.: Turbulent Boundary-Layer Heat Transfer from Rapidly Accelerating Flow of Rocket Combustion Gases and Heated Air, Advances in Heat Transfer, 2 (1965).

10) Detra, R. W., Kemp, N. H. Riddell, F. R.: Addendum to Heat transfer to Satellite Vehicles Re-entering the Atmosphere, Jet Propulsion, 27 (1957).

11) Murakami, A.: Empirical Method of Total Pressure Loss Estimation of Subsonic Diffuser, JAXA Research memorandum, JAXA-RM-04-002, 2004 (in Japanese).

12) Kanda, T., Tomioka, S., Ueda, S., Tani, K., Wakamatsu, Y.: Design of Sub-Scale Rocket-Ramjet Combined Cycle Engine Model, IAC paper IAC-05-C4.5.03, 2005. 